\title{
Refractory Neurofibromatosis Type 1
}

National Cancer Institute

\section{Source}

National Cancer Institute. Refractory Neurofibromatosis Type 1. NCI Thesaurus. Code C155986.

Neurofibromatosis type 1 that is resistant to treatment. 